\title{
Blue honeysuckle introduction and breeding in the Central Siberian Botanical Garden (Novosibirsk, Russia)
}

\author{
Irina G. Boyarskikh ${ }^{1}$ * \\ ${ }^{1}$ Central Siberian Botanical Garden of the SB RAS, Zolotodolinskaya Str., 101, Novosibirsk, 630090, \\ Russia
}

\begin{abstract}
The use of the blue honeysuckle Lonicera caerulea subsp. altaica (Caprifoliaceae) for breeding resulted in the novel forms exceeding the parent ones in early maturity, fruit mass, biologically active compounds content and the crown shape allowing the mechanized harvesting.
\end{abstract}

\section{Introduction}

Subsection Caerulaea Rehd., or blue honeysuckles (Lonicera genus of the Caprifoliaceae Juss. family) according to the M.N. Plehanova's classification [1], in Eurasia consists of three endemic diploid species Lonicera iliensis Pojark., L. edulis Turcz. ex Freyn, L. boczkarnokowae Plekhanova nom. nov. (=L. regeliana Boczkarn.) and a tetraploid species L. caerulea L., embracing seven subspecies of $L$. caerulea subsp. caerulea, L. caerulea subsp. emphyllocalyx (Maxim) Plekhanova comb. nov., L. caerulea subsp. altaica (Pall.) Plekhanova comb. nov., L. caerulea subsp. pallasii (Ledeb.) Browich, L. caerulea subsp. stenantha (Pojark) Hult. ex Skvortsov, L. caerulea subsp. kamtschatica (Pojark.) Plekhanova comb. nov., L. caerulea subsp. venulosa (Maxim) Worosh.

Blue honeysuckle is spread in the taiga zone of Eurasia and North America. On most of their area their berries have bitter taste and are not edible. Till the middle of the $20^{\text {th }}$ century the species of the subsection were not considered even as a potentially edible plant. Only in the Far East [2], in the north of China and the island of Hokkaido in Japan the fruits of $L$. caerulea subsp. kamtschatica, L. caerulea subsp. venulosa, L. caerulea subsp. emphyllocalyx and L. boczkarnokowae were used as food $[3,4]$. The natural populations of L. caerulea subsp. kamtschatica and L. caerulea subsp. Venulosa became the source for breeding the first cultivars of blue honeysuckle. However, most of the cultivars of the Far East provenance decreased their productivity in the steppe and forest-steppe areas of the West Siberia due to the continental climate. In the region the species L. caerulea subsp. altaica seemed to have better prospects in the intensive breeding programs, as the species combines a number of economically valuable traits, such as high productivity, early maturity, drought resistance, firm attachment of compound fruits and high bioflavonoid content. The dominance of bitter-tasting fruits in the offspring made it difficult to use the $L$.

\footnotetext{
* Corresponding author: irina 2302@mail.ru
} 
caerulea subsp. altaica as initial source material, thus urging to find natural populations of the subspecies with prevalence of individuals without the bitter taste of their fruits.

In ethnic medicine the blue honeysuckle species have been known for a long time as medicinal plants [5]. Numerous studies confirmed the beneficial for human health effects of L. caerulea berries, such as antioxidant activity, antibacterial, immunological [7], antiinflammatory, neuroprotective, antitumor and antidiabetic activities of the blue honeysuckle preparations [8]. The main components of biologically active phenolic compounds (PC) in L. caerulea fruits are such flavonoids as anthocyanins, flavonols and flavons, hydroxycinnamic acids (HCA) and flavans [8].

Differential qualitative and quantitative fruit PC contents were found in different $L$. caerulea varietes and genotypes [9]. The fruit PC profiles were also found to be affected by the plant growing environment [9]. It is known that successive selection of the blue honeysuckle plants by their fruits sensory properties, size, yield and cold resistance may result in decreasing both the total PC content as well as the ratio of their specific groups [10]. Therefore the information about the fruit PC content is indispensable for breeding and introduction of varieties obtained using the species of the other geographical provenances.

The last decades saw the active use of blue honeysuckle in agricultural production in temperate regions [3, 5, 11]. Since 2016 in Russia in the West Siberia agricultural plantations of blue honeysuckle are started every year in the Tomsk and Novosibirsk regions, currently totaling 300 ha. So the situation urges for finding new source material for selection, focusing on creating and breeding of varieties suitable for mechanized harvesting.

The aim of the work was to compare agriculturally valuable traits, including the fruit polyphenolics profiles of the blue honeysuckle varieties bred by the Central Siberian Botanical Garden (CSBG) in the forest-steppe near the Ob River (Novosibirsk, Russia).

\section{Material and methods}

Fruit mass, taste and attachment were determined in fruits of the 17 blue honeysuckle forms bred by the CSBG on the right bank Ob River area in the forest-steppe by using standard methods [12].

The individual PC compounds in fruits was determined for three varieties of different ecological and geographical provenances, bred by the Lisavenko Research Institute of Horticulture, namely Zolushka (L. caerulea subsp. Kamtschatica), Pamyati Guidzyuka ( $L$. caerulea subsp. venulosa), Berel (a hybrid between L. caerulea subsp. altaica and $L$. caerulea subsp. kamtschatica), as well as ten CSBG selected L. caerulea forms. Technically ripe fruits were collected and frozen at $-18^{\circ} \mathrm{C}$.

The flavonoid and HCA content was estimated using HPLC technique. Identification of individual compounds of the analyzed in fruit extracts, and estimation of their contribution into the total PC content was performed by using HPLC-MS system. The system included the liquid chromatographer «Agilent 1200» (with diode-matrix detector) and the hybrid quadrupole time-of-flight mass-spectrometer micrOTOF-Q (Bruker Daltonics, USA); the Zorbax SB-Aq column of $2.1 \times 150 \mathrm{~mm}$ and $3.5 \mu \mathrm{m}$ in diameter; $2 \% \mathrm{HCOOH}-\mathrm{ACN}$ with a linear gradient of acetonitrile (ACN) from 5 to $25 \%$ from 0 till $15 \mathrm{~min}$, and from 25 to $90 \%$ from 20 till $25 \mathrm{~min}$. The flow rate was $0.2 \mathrm{ml} / \mathrm{min}$. The UV-Vis detection was carried out using the five wavelengths of 255/16, 340/32, 370/80, 460/80 and 650/80 nm. The working parameters of the MS detection were as following: ionization with electrospray under atmospheric pressure (API-ES), scanning for anions in the $\mathrm{m} / \mathrm{z}=100-1000$ range, the desiccating gas (nitrogen) flow rate of $8 \mathrm{~L} / \mathrm{min}$ with its temperature of $240^{\circ} \mathrm{C}$, and the pressure of 2.0 Bar at the ion funnel.

Comparative analysis of the individual PC composition of the fruit extracts was performed on the basis of the integral intensity of the chromatographic signal of a 
component: for anthocyanins at wavelength of $460 \pm 40 \mathrm{~nm}$, and for HCA, flavonols and flavons at $340 \pm 16 \mathrm{~nm}$.

By using as reference standards the anthocyanin content in the blackberry extracts, and rutin and chlorogenic acid reference samples we determined the anthocyanin content as equivalent to cyanidin-3-glucoside, and the flavonols and flavons contents as equivalent to rutin, whereas the HCA content was calculated as equivalent to the chlorogenic acid, using the formula $\mathrm{Cx}=100 \cdot \mathrm{S}_{1} \cdot \mathrm{C}_{\mathrm{ref}} \cdot \mathrm{V} / \mathrm{S}_{\mathrm{cr}} \cdot \mathrm{m}$, where: $\mathrm{S}_{1}$ is a peak area of an individual component in the analyzed sample; $\mathrm{C}_{\text {ref }}$ is a concentration in a reference standard; $\mathrm{V}$ is the volume of the extragent, $\mathrm{ml}$; $\mathrm{S}_{\text {ref }}$ is a peak area in a reference sample; and $\mathrm{m}$ is an aliquot mass, $\mathrm{mg}$.

The flavonoid content was determined as a sum of quercetin glucosides, whereas the flavon content was estimated as the sum of luteolin and apigenin contents together with their free aglicons. The HCA derivatives were estimated as sum total of neochlorogenic, dicaffeoylquinic, chlorogenic acids and their isomers.

The relative standard deviation for repeatability while determining phenolic compounds was s.d. $=0.010$.

\section{Results and discussion}

The CSBG has been developing the introduction population of blue honeysuckle since 1970. The first sample plants were collected from the natural populations in the Altai Mountains. During the following years the collection increased due to the breeding material provided by the Lisavenko Research Institute of Horticulture, its experimental station in the Bakchar village (Tomsk region, Russia) and the N.I. Vavilov Research Institute of Plant Genetic Resources (Saint-Petersberg, Russia). In 1998 a field breeding plot was set up, where seedlings resultant from the spontaneous pollination of samples from the natural populations in the Altai Mountains were planted, namely no.39, no.45 and no.72. Then from these seedlings some promising varieties with big (up to $2.0 \mathrm{~g}$ ) firmly attached fruits with dissert taste and strong peel (Table 1) were selected. The breeding program was also targeted at selecting the varieties with the shrub crown well above the ground surface, moderate branch density, flexible skeletal branches and with plant height and diameter not exceeding $1.5 \mathrm{~m}$, suitable for mechanized harvesting.

Table 1. Fruit properties of selected forms obtained by spontaneous pollination of $L$. caerulea subsp. Altaica samples

\begin{tabular}{|l|c|c|l|c|}
\hline \multirow{2}{*}{ Variety } & \multicolumn{2}{|c|}{ Fruit mass, } & \multicolumn{1}{c|}{ Taste } & $\begin{array}{c}\text { Fruit attachment, } \\
\text { score }\end{array}$ \\
\cline { 2 - 3 } & Mean & Maximum & & 3 \\
\hline Tsarevna (3-3-03) & 1.3 & 1.5 & Sour-sweet & 3 \\
\hline Marmaladnaya (3-10-03) & 1.4 & 1.5 & Sweet & 4 \\
\hline Elan (4-5-03) & 1.1 & 1.6 & Sweet-sour & 3 \\
\hline Capella (4-7-03) & 1 & 1.4 & Sour-sweet & 4 \\
\hline Krepkaya (4-8-03) & 1.1 & 2.0 & Sweet-sour & 4 \\
\hline Verhkubinskaya (4-10-03) & 1.2 & 1.5 & Sour-sweet & 4 \\
\hline Multa (4-16-03) & 1.1 & 1.9 & Sweet-sour & 4 \\
\hline Yadrenaya (9-4-03) & 1.3 & 1.9 & Sour & \\
\hline
\end{tabular}


Simultaneously the hybridization of the varieties of distant geographical provenances was carried out: L. caerulea subsp. altaica (Salute cultvar), L. caerulea subsp. venulosa (Tomichka, Pamyati Guidzyuka, Parabelskaya cultivars) L. caerulea subsp. kamtschatica (Goluboye vereteno, Zolushka, Kaamchadalka cultivars), the hybrid between $L$. caerulea subsp. altaica $\times$ L. caerulea subsp. kamtschatica (Berel cultivar). As a results of the crosspollination of three subspecies of blue honeysuckle the choice forms were obtained (Table 2), exceeding the parental forms in fruit mass and productivity, as well as in biologically active compounds' content. The crossing combinations, resulting in the positive transgression in biologically active phenols content, were also found [13].

Table 2. Fruit properties of the selected blue honeysuckle varieties resultant from the crossing of the varieties of distant geographical provenances.

\begin{tabular}{|c|c|c|c|c|}
\hline \multirow{2}{*}{ Variety } & \multicolumn{2}{|c|}{ Fruit mass, $\mathbf{g}$} & \multirow{2}{*}{ Taste } & \multirow{2}{*}{$\begin{array}{c}\text { Fruit attachment } \\
\text { score }\end{array}$} \\
\hline & Mean & Maximum & & \\
\hline Doch Zolushki (1-7) & 1.1 & 1.4 & Sourish-sweet & 3 \\
\hline Freya (2-48) & 1.2 & 1.6 & Sourish-sweet & 2 \\
\hline Golubaya mechta (3-22) & 1.1 & 1.4 & Sourish-sweet & 3 \\
\hline Aina (3-25) & 1.0 & 1.3 & Sourish-sweet & 4 \\
\hline Vega (3-28) & 1.2 & 1.4 & Sourish-sweet & 2 \\
\hline Ayula (3-31) & 1.0 & 1.3 & Sourish-sweet & 3 \\
\hline Uimonskaya (3-32) & 1.0 & 1.2 & Sourish-sweet & 3 \\
\hline $2-11$ & 0.9 & 1.8 & Sweetish-sour & 3 \\
\hline $2-23$ & 0.7 & 1.0 & Sweetish-sour & 3 \\
\hline
\end{tabular}

The individual composition of PC in the fruits of the selected L. caerulea forms was characterized by HPLC (Table 3). The anthocyanins are known to be the main bioflavonoids in honeysuckle fruits $[8,10,13]$. We found that the main anthocyanin in the studied $L$. caerulea fruit samples was represented by cyanide-3-glucoside (up to $91 \%$ of total bioflavonoids), whereas cyanidin-3,5-diglucoside, cyanidin-3-rutinoside, pelargonidin-3-glucoside, peonidine-3-glucoside were the minor components. Chlorogenic, neochlorogenic and dicaffeoylquinic were identified among the hydroxycinnamic acids; in flavonols and flavons group glucosides and rutinosides of quercetin, luteolin and apigenin were identified.

The maximal anthocyanin content $(875-1079 \mathrm{mg} / 100 \mathrm{~g})$ was found in the fruits of such varieties as Multa, Yadrenaya, Marmaladnaya, Tsarevna, No. 2-11 and No. 2-23, obtained with participation of $L$. caerulea subsp. altaica, as well as Pamyati Guidzyuka, obtained with participation of $L$. caerulea subsp. venulosa. The minimal content (510-574 mg/100 g) was found in the varieties of the Kamchatka provenance, including the fruits of the hybrid between $L$. caerulea subsp. altaica $\times$ L. caerulea subsp. kamtschatica (Berel cultivar).

Quercetin rutinoside (rutin), chlorogenic and dicaffeoylquinic acids were present in extracts from the fruits of all studied samples. The selected form Tsarevna had no flavons in its extracts. The composition profiles of minor components varied. Earlier significant differences in the major PC content in fruits produced by some $L$. caerulea subspecies were found [13]. The PC composition variation in fruits of the selected $L$. caerulea varieties most 
likely depends on the contribution of the initial forms of different provenances which grow on the CSBG experimental plot.

Table 3. Flavonoid and hydroxycinnamic acids content in fruits of different $L$. caerulea varieties, $\mathrm{mg} / 100 \mathrm{~g}$ (fresh mass)

\begin{tabular}{|c|c|c|c|c|c|c|c|c|c|c|c|}
\hline \multirow{2}{*}{ Phenolic compounds } & \multicolumn{11}{|c|}{ Varieties and selected forms* } \\
\hline & 1 & 2 & 3 & 4 & 5 & 6 & 7 & 8 & 9 & 10 & 11 \\
\hline Cyanidin glucoside & 845 & 490 & 507 & 548 & 875 & 690 & 692 & 1038 & 800 & 862 & 924 \\
\hline Chlorogenic acid & 95 & 47 & 50 & 56 & 82 & 58 & 55 & 73 & 78 & 72 & 107 \\
\hline Neochlorogenic acid & 6 & 3 & 4 & 3 & 5 & 4 & 5 & 0 & 0 & 0 & 6 \\
\hline $\begin{array}{l}\text { Quercetin glycoside } \\
(\mathrm{m} . \mathrm{m} . .=742.19)\end{array}$ & 2 & 0 & 0 & 0 & 0 & 0 & 3 & 0 & 0 & 0 & 0 \\
\hline $\begin{array}{l}\text { Quercetine glycoside } \\
(\mathrm{m} . \mathrm{m} .=756.20)\end{array}$ & 3 & 0 & 0 & 2 & 4 & 0 & 3 & 5 & 3 & 3 & 0 \\
\hline $\begin{array}{l}\text { Luteolin glycoside } \\
(\mathrm{m} . \mathrm{m} .=596.14)\end{array}$ & 0 & 0 & 0 & 0 & 0 & 0 & 0 & 3 & 0 & 0 & 0 \\
\hline $\begin{array}{l}\text { Quercetin glycoside } \\
\text { (m.m. }=610.15)\end{array}$ & 18 & 0 & 0 & 7 & 0 & 8 & 17 & 0 & 0 & 0 & 13 \\
\hline $\begin{array}{l}\text { Quercetin glycoside } \\
(\mathrm{m} . \mathrm{m} . .=610.15)\end{array}$ & 37 & 18 & 15 & 23 & 7 & 28 & 39 & 4 & 5 & 10 & 31 \\
\hline $\begin{array}{l}\text { Luteolin glycoside } \\
\text { (m.m. }=580.14)\end{array}$ & 0 & 0 & 0 & 1 & 0 & 0 & 0 & 10 & 0 & 0 & 4 \\
\hline $\begin{array}{l}\text { Quercetin glycoside } \\
\text { (m.m.=464.10) }\end{array}$ & 0 & 4 & 3 & 6 & 20 & 5 & 0 & 21 & 6 & 5 & 5 \\
\hline $\begin{array}{l}\text { Luteolin rutinoside } \\
(\mathrm{m} . \mathrm{m} .=624.17)\end{array}$ & 0 & 0 & 0 & 4 & 10 & 0 & 0 & 16 & 0 & 0 & 0 \\
\hline $\begin{array}{l}\text { Luteolin glycoside } \\
\text { (m.m. }=448.10)\end{array}$ & 10 & 6 & 7 & 9 & 13 & 23 & 12 & 13 & 6 & 0 & 8 \\
\hline $\begin{array}{l}\text { Dicaffeoylquinic } \\
\text { m.m.=516.11 }\end{array}$ & 17 & 12 & 14 & 37 & 28 & 43 & 22 & 37 & 25 & 11 & 24 \\
\hline $\begin{array}{l}\text { Apigenin glycoside } \\
\text { (m.m. }=432.10)\end{array}$ & 0 & 0 & 0 & 0 & 0 & 0 & 0 & 5 & 0 & 0 & 0 \\
\hline Anthocyanins & 884 & 510 & 526 & 574 & 918 & 704 & 716 & 1079 & 832 & 898 & 947 \\
\hline HCA $^{* *}$ & 117 & 62 & 69 & 98 & 115 & 105 & 82 & 110 & 103 & 83 & 137 \\
\hline \begin{tabular}{|l|} 
Flavonols \\
\end{tabular} & 60 & 22 & 18 & 38 & 30 & 40 & 62 & 30 & 14 & 18 & 49 \\
\hline Flavons & 10 & 6 & 7 & 14 & 23 & 23 & 12 & 46 & 6 & $\mathbf{0}$ & 12 \\
\hline Total polyphenols & 1072 & 655 & 620 & 724 & 1087 & 872 & 872 & 1266 & 954 & 999 & 1146 \\
\hline
\end{tabular}

Note: * 1 - Pamyati Guidzyuka, 2 - Zolushka, 3 - Doch Zolushki, 4 - Berel, 5 - Multa, 6 - Capella, 7 - Krepkaya, 8 - Yadrenaya, 9 - Marmeladnaya, 10 - Tsarevna, 11 - 2-23; ** HCA hydroxycinnamic acids.

The study was supported by the Ministry of Science and Higher Education of the Russian Federation (project AAAA-A17-117012610053-9 for the Central Siberian Botanical Garden, SB RAS). Material from the Bioresource Research Collection No.USU 44053of the Central Siberian Botanical Garden (SB RAS, Novosibirsk) was used for preparing the article.

\section{References}


1. M.N. Plekhanova, Transactions on applied botany, genetics and selection, 161, 57-68 (2007) (in Russian)

2. I.K. Guidzyuk, Honeysuckle with edible fruits (Tomsk, 1981) in Russian

3. Huo Jun-Wei, Yang Guo-Hui, Sui Wei, Yu Ze-Yuan, Acta Horticulturae Sinica, 32, 159164 (2005)

4. L Fu, H Okamoto, $\mathrm{Y}$ Hoshino, $\mathrm{Y}$ Esaki, $\mathrm{T}$ Kataoka, $\mathrm{Y}$ Shibata, Engineering in Agriculture, 4, 12-17 (2011)

5. E. Lefol Haskap market development - the Japanese opportunity, (2007)

6. H.P.V. Rupasinghe, L.J. Yu, K.S. Bhullar, B. Bors, J. Can, Plant Sci, 92, 1311-1317 (2012)

7. M. Minami, M. Nakamura, T. Makino, Hindawi Bio Med Research International, ID 1797930 (2019)

8. H.P.V. Rupasinghe, N. Arumuggam, M. Amararathna, A.B.K.H. De Silva J. Funct. Foods, 44, 24-39 (2018)

9. M. Senica, F. Stampar, M. Mikulic-Petkovsek, Scientia Horticulturae, 238, 215-221 (2018)

10. S.A. Streltsina, A.A. Sorokin, M.N. Plekhanova, E.V. Lobanova, Agrar. Russia, 6, 6772 (2006) (in Russian)

11. B. Bors, J. Thomson, E. Sawchuk, P. Reimer, R. Sawatzky, T. Sander Haskap breeding and production - final report. Saskatchewan Agriculture: Regina, (Saskatchewan, Canada, 2012)

12. Program and methods to study the cultivars of fruit-, berry- and nut-producing cultures, (Orel, VNIIPSK, 1999) in Russian

13. I.G. Boyarskih, Y.V. Yushkova, E.I. Chernyak, S.V. Morosov, The Herald of the Altai State Agrarian University, 3, 39-46 (2011) in Russian 